\title{
EL UMBRAL SAGRADO (ENTRE LA EXPERIENCIA MÍSTICA Y EL RITUAL PAGANO)
}

\author{
Melvin Campos Ocampo
}

\begin{abstract}
RESUMEN
Este artículo analiza la ambigüedad de la experiencia mística que padece la instancia narrativa en el relato "Misa de ocho", de Yolanda Oreamuno. La ambigüedad radica en que este arrebato místico cristiano está revestido de paganismo: el rito se hace íntimo mediante elementos sensoriales (la luz, el color, la música), y culmina en un éxtasis danzante cercano al arrebato erótico. Así, es una epifanía mística no católica, sino propia de las religiones precristianas, vinculadas con la tierra, lo femenino, lo físico y lo erótico.

Palabras clave: Yolanda Oreamuno, "Misa de ocho”, éxtasis místico,paganismo, danza sagrada.
\end{abstract}

\begin{abstract}
This article analyzes the ambiguity of the mystical experience suffered by the narrative instance in the short story "Misa de ocho", by Yolanda Oreamuno. This ambiguity is produced because the Christian mystical rapture is tainted by paganism: the rite becomes intimate through physically sensitive elements (light, colour, music), and ends in a dancing outburst that is very close to an erotic rapture. Thus, it is a non Catholic epiphany, rather than one related to pre- Christian religions, linked to the Earth, the feminine, the physical and the erotic.

Key words: Yolanda Oreamuno, "Misa de ocho", mystic ecstasy, paganism, sacred dance.
\end{abstract}

Mística, la oscura percepción de sí del reino que está fuera del yo, del ello.

Sigmund Freud. Conclusiones, ideas, problemas.

... y buscas en el fosforescente rocío del mar que moja tus labios el beso de tu único amante, el Demonio.

Carlos Fuentes. Terra Nostra.

Melvin Campos Ocampo. Profesor de la Universidad de Costa Rica y de la Universidad Estatal a Distancia. Correo electrónico: melvin.campos@ucr.ac.cr

Recepción: 17- 9- 2008

Aceptación: 23- 10- 2008 


\section{Ante Dios y vosotros...}

Más allá de cualquier racionalidad (o racionalismo), existen maravillas y misterios que el ser humano aún no ha logrado responder y es probable que nunca lo haga: la vida, la muerte, la existencia, el universo, el destino. Algunos especulan posibles respuestas a esos enigmas, para encontrar alguna esperanza en un mítico más allá; otros ya la hemos abandonado. Pero, independientemente de la religión que se profese o de la divinidad a que se rinda culto, la experiencia mística acontece a todos los seres humanos, inclusive a los ateos. Y ésta radica, fundamentalmente, en el asombro que puede embargar la mente y apretar el corazón ante las cataratas del Iguazú, ante la conciencia de que las aves vienen de los dinosaurios, ante la abrumadora eternidad del espacio sideral o el nacimiento de un niño. Legión es el nombre que hemos dado a ese sobrecogimiento: Shiva, Changó, Jurakán, Rha, Démeter, Alá, Yahvé, Dios, Naturaleza.

Yolanda Oreamuno expone una particular concepción de ese arrebato místico, en su relato "Misa de ocho" (1937). Este cuento, sin embargo, no refiere apariciones divinas, alucinaciones sacras o encuentros angelicales. En realidad, no ocurre nada con claridad; ni siquiera se narra la misa abiertamente. Se trata de una metafórica descripción de ambientes, colores, sonidos y ritmos; sensaciones que provocan en la instancia narrativa un singular arrebato místico danzante. Esta peculiar forma de vincularse con la divinidad católica es la que ha llamado mi atención y a cuyo análisis me abocaré en adelante.

\section{La mística del cuerpo (cómo ver a Dios y no morir en el intento)}

Ya desde el título, "Misa de ocho", el texto se vincula con lo religioso; específicamente, con el catolicismo y con su rito fundamental, ése que permite una cercanía con la divinidad: la misa ${ }^{1}$. Ahora bien, todo ritual mantiene el esquema de la repetición sistemática: es un acto reiterado, mediante el cual se representa el eterno retorno, el tiempo cíclico del fin y del reinicio, de muerte y de renacimiento, propio del universo simbólico del mito. En el rito predomina lo que Mircea Eliade llama un tiempo litúrgico (2001: 29). Tal es el caso, por ejemplo, de las letanías católicas o los mantras budistas. Es comprensible, entonces, que la propia instancia narrativa ${ }^{2}$ introduzca el relato haciendo hincapié en la regularidad con que asiste al rito: "Yo voy a misa de ocho todos los domingos. A la Catedral" (139). Así pues, esta introducción ubica al lector en un contexto ritualizado, de la reiteración, en un escenario místico.

Inmediatamente, la instancia narrativa empieza a exponer una serie de descripciones sensoriales a partir de varias metáforas visuales, relacionadas con la luz y con el color. Ambos elementos aparecen personificados, realizando acciones específicas en la Catedral. Particularmente, la luz primero inunda el recinto, lo densifica, lo satura (139) y, luego, tiene actitudes de adoración a la divinidad: "La maravillosa luz de verano lo va llenando todo, se sienta en las bancas, se arrodilla sobre los reclinatorios, se acuesta en el mosaico y se soba suavemente con las molduras doradas del altar" (140).

Podemos notar que la luz realiza dos tipos distintos de acción. Uno de ellos está vinculado con el rito católico, pues son las prácticas que los feligreses normalmente llevan a cabo durante la misa: sentarse en las bancas y arrodillarse en los reclinatorios. Sin embargo, la luz ejecuta otras acciones que no son comunes en el rito católico: acostarse en el mosaico y restregarse contra el altar. De hecho, este otro tipo de acto sería más bien punible en 
medio de una misa, si un feligrés se acostara en el piso o empezara a sobarse contra el altar. Esta dualidad en las acciones que realiza la luz nos plantea, ya desde ahora, una cierta ambigüedad en el relato: es un misticismo distinto, con un cierto matiz erótico. Pero dejemos esto para más adelante.

A continuación, la gente ingresa a la misa. Lo peculiar en este momento es que los asistentes no tienen valor alguno para la instancia narrativa: se trata de una masa despersonalizada -inclusive el texto dice: "esta gente no tiene importancia" (140)-, las personas se vuelven irrelevantes. Esto permite al relato hacer hincapié en el carácter animado (¿animista?) del siguiente "personaje” que ingresa en el recinto sagrado, el color: "Ha salido el ambiente y ha entrado el color. [...] El color que entra no es quién vestido de esta manera, no es la cabeza dorada o morena peinada en tal o cual forma: es un personaje solitario y uniforme" (140). El color, sin embargo, no realiza acciones como la luz: solamente entra a presenciar el rito católico. Esta secuencia de metáforas visuales, suerte de alucinación, termina justo cuando la ceremonia da inicio. En adelante, el carácter sensorial con que la instancia narrativa reviste a la misa (o más bien, al preámbulo de ésta), pasa de ser visual a ser auditivo y entran a escena las metáforas musicales. "La misa y la música han empezado simultáneamente. Paralelas e iguales, se desarrollan respondiendo la una a la otra, imitando la una a la otra. A ratos la misa es música y otras veces, la música es ceremonia mística” (140-1).

Como vemos, el rito católico y la música son equivalentes: empiezan al unísono, transcurren "paralelas e iguales", se imitan mutuamente; en otras palabras: son idénticas, dos caras de una moneda. El relato continúa, luego, con una descripción metafórica de las acciones que realiza la música/ misa; me interesa resaltar, sin embargo, la igualdad entre ambos elementos, pues ello implica que toda reacción provocada por la música, será también provocada por la ceremonia y viceversa, en la medida en que son intercambiables. Veamos, entonces, cuál es esa reacción que la misa/ música provoca en la instancia narrativa:

\footnotetext{
Y vuelve otra vez la música a correr por la iglesia, a buscarse en los rincones, a brincar de un punto a otro, a ponerse seria y santurrona, a bailar...
}

\footnotetext{
A bailar. Sí. ¿Por qué no he de bailar yo? ¿Por qué no he de bailar en la imaginación como otros rezan en la boca solamente? ¿Por qué no? (143).
}

En efecto, la música/ misa compele a la instancia narrativa a expresar su arrebato místico mediante el baile. Esto es comprensible pues la igualdad entre rito católico y música implica que la posesión mística será también una posesión musical, o sea baile: el arrebato sagrado es arrebato danzante.

Resulta particularmente llamativo que esta unión mística no sea del orden metafísico - como cabría esperar al tratarse de un vínculo con la divinidad-, sino que es provocada más bien por un impulso físico, sensorial (la música), y se manifiesta en lo corporal mediante la danza. Esta expresión mística a través del cuerpo, hace que la instancia narrativa se sienta literalmente poseída por la música/ misa: "Hay que bailar esta danza mística o pagana; hay que dejarse tocar por la música de un lado, de otro, hay que dejar que ella, creación imaginativa máxima, haga este baile que le dedico a Dios" (143, las cursivas son mías). Deseo resaltar la afirmación de que la danza es "mística o pagana", pues ello sugiere la explicación que posteriormente haré de ese arrebato "físicomístico". Por ahora, veamos hasta dónde llega la posesión: 


\begin{abstract}
Viene la música por aquí, por las piernas, empuja, hay que doblar, suave, flexible. Sube ahora rastreando el cuerpo y haciendo ondas resbalosas; el cuerpo se hace elástico y es ella la que mueve los brazos, la que dobla la cabeza, la que hace avanzar. Es ella la que pasando brusca de un lado, hace dar violentamente vuelta, la que subiendo por las piernas hace este salto elástico y gigante, la que tremolando de todos lados, hace vibrar vertiginosamente... (143).
\end{abstract}

Resumo: la música empuja, sube resbalosa, avanza brusca, sube por las piernas, tiembla y hace vibrar. Nótese el fuerte matiz erótico de los significantes usados. Luego, la instancia narrativa plantea que es necesario dejarse poseer por la música; hecho que sería el punto culminante del arrebato místico:

Hay [...] que dejarse por ella insinuante, por ella brusca, por ella violenta, por ella esquiva, por ella arrolladora, para bailar, para moverse, para arrastrarse, hasta el jadeo, hasta el desequilibrio, hasta el paroxismo, hasta el aflojamiento muscular, hasta el descanso y la inercia perpetua (143-4).

Estos dos últimos fragmentos que he citado exponen el punto máximo de la epifanía sagrada, desde el arrebato hasta el clímax. Es notable cómo los significantes guardan una estrecha relación con un acto erótico, desde la seducción y el desenfreno, hasta el clímax y la extenuación. Y justamente a este punto quería llegar: según la descripción que hace el relato, la experiencia mística es de carácter sensorial, corpóreo, erótico. La vinculación con la divinidad es un arrebato muy parecido a la posesión sexual ${ }^{3}$. A continuación aventuraré una interpretación de ese particular arrebato místico/ corporal.

\title{
3. Por sus actos los conoceréis (la bruja Oreamuno)
}

Si bien la posesión erótica sagrada es común entre las religiones "paganas", en la tradición cristiana aparece muy poco. De hecho, sólo la Virgen María resulta embarazada por Dios y no precisamente por un arrebato erótico: más bien por un acto sublimado, como el embarazo de Dánae por parte de Zeus en forma de lluvia de oro (Graves 2002: 316). Es conocido, además, el repudio del cristianismo por todo lo relacionado con la fisionomía, en busca de un metafísico más allá en donde impera la asexualidad (Nietzsche 1999: 35). Baste recordar la interpretación alegórica que hace el dogma católico del Cantar de los Cantares, con Dios como el amante y el alma como la amada. Desde esta perspectiva, es claro que el catolicismo no permitiría una forma de adoración sagrada como la que aparece en el relato y, entonces, es necesario buscar en otras tradiciones religiosas para encontrar el sustrato cultural que yace bajo la experiencia mística erótica/ corporal en "Misa de ocho".

Primeramente, recordemos que la instancia narrativa describe el arrebato sagrado como una "danza mística o pagana" (143). Ahora bien, dado que en castellano, la conjunción “o" posee el carácter doble de igualdad y disyunción (RAE 2001: 1601), es factible interpretar que, en el relato, ambos bailes pueden ser equivalentes: da igual que se trate de un baile pagano o católico, si tal cosa fuera posible. En otras palabras, el texto plantea la posibilidad de que la experiencia mística suceda independientemente de la divinidad que se adore o de la religión que se profese. Se trata, pues, de una unión sagrada que acontece en el umbral entre el catolicismo y el paganismo.

Esta intercambiabilidad que plantea la instancia narrativa entre lo pagano y lo místico, nos indica el camino para buscar el origen de este baile religioso ${ }^{4}$. Decíamos que la experiencia mística propuesta en el relato de Yolanda Oreamuno, está revestida de elementos sensoriales y físicos (la luz, el color, la música), para culminar en un éxtasis danzante muy 
cercano al arrebato erótico. Adelantemos las conclusiones: se trata de tipo de epifanía mística propia de las religiones precristianas, vinculadas con la tierra, con lo femenino, con lo físico y con lo erótico. Veamos.

Como es sabido, antes de la imposición del cristianismo, por toda Europa estaban muy difundidos los cultos a la tierra, como forma de agradecimiento por las cosechas obtenidas y solicitud de los cultivos venideros. Estas religiones estaban centradas en el poder fecundo y regenerativo de la tierra, entendida ésta como la madre cósmica, tierra gentil, pródigo suelo que dulce abrigo y sustento nos da:

El trabajo agrícola es un rito; no sólo porque se realiza sobre el cuerpo de la tierra-madre y porque desencadena las fuerzas sagradas de la vegetación, sino también porque implica la integración del labrador en ciertos periodos de tiempo [la ciclicidad mítica del año y sus estaciones]... (Eliade 1992: 300 , las cursivas son mías).

Estas religiones ctónicas, como vemos, refieren directamente a lo físico, corpóreo, material, en la medida en que, si bien se puede adorar a una entidad metafísica como personificación mítica de la tierra (llamémosla Diosa Madre (Graves 1998: 19-21; Eliade 1992: 220)), es a su manifestación física -la tierra- a quien se adora directamente. Es comprensible, entonces, que el vínculo con la divinidad se establezca a través de lo corporal. Y así, en efecto, los ritos vinculados con la fertilidad de la tierra se llevan a cabo en la fisionomía de los participantes ${ }^{5}$, mediante el contacto físico o la embriaguez, como en los cultos dionisiacos prehelénicos (Eliade 1992: 324), o con el uso de drogas alucinógenas para agudizar los sentidos y percibir a las divinidades (Chevalier 1999: 1072). La divinidad no se revela por fe, sino a través de sensaciones corporales.

Ahora bien, volviendo al relato de Oreamuno recordemos la enorme importancia que se le otorga a lo sensorial en una epifanía sagrada. En el texto, el vínculo con la divinidad no se desarrolla mediante revelaciones de fe ni intuiciones metafísicas, sino a través de sensaciones físicas: visuales (relacionadas con la luz y el color que entran a la misa), auditivas (la música que embelesa y posee a la instancia narrativa) y corporales (el arrebato místico culmina con el baile). Así, es mediante el cuerpo que el sujeto se une a la divinidad. De manera que este modo físico de experimentar al dios nos ubica en un universo pagano pues, en el relato, el cuerpo es justamente el modo de sentir lo divino, es el punto primordial de unión cósmica; contrario al modo metafísico del cristianismo, para quien la unión acontece entre el alma y Dios (Daxelmüller 1997: 94).

Resulta sugerente pensar que, si en el relato la unión sagrada se realiza mediante el cuerpo, entonces la experiencia mística será totalmente íntima, personal: cada persona experimentará en su cuerpo a la divinidad de formas diferentes. Esta posibilidad reforzaría el hecho de que, para la instancia narrativa, el baile sea una suerte de oración personal, la manera propia de vincularse con la divinidad. Este carácter íntimo del arrebato sagrado es, justamente, lo que le permite al sujeto establecer la conexión con la divinidad mediante un modo particular: el baile. Por ello pregunta: “Por qué si otros rezan, yo no puedo bailar?” (144); la experiencia mística personal de la instancia narrativa es: "este baile que le dedico a Dios" (143).

Esta epifanía particular -el uso de la danza como forma de adoración- también está vinculada con los cultos antiguos a la fertilidad de la tierra, donde el baile ritual permitía la unión mística: "las danzas rituales son un medio de restablecimiento de relaciones entre la tierra y el cielo, reclamen la lluvia, el amor, la victoria o la fertilidad, o incluso la extinción 
en la Unidad divina" (Chevalier 1999: 396, las cursivas son mías). Nótese que estas danzas, mediante las cuales se produce el arrebato místico, anulan la existencia individual del yo, para disolverlo en la totalidad cósmica del dios. Así, el baile sagrado produce el éxtasis místico por medio de la extenuación física; o, dicho en otras palabras, es mediante el arrebato corporal que sucede la posesión mística. Reitero lo obvio: la danza no tiene cabida en el catolicismo: en un rito católico nadie se pondría a bailar de felicidad por haber encontrado a Dios ${ }^{6}$. Por ello, es en el sustrato pagano donde encontramos la explicación para este baile religioso.

El paso del éxtasis danzante al arrebato erótico es comprensible, pues ambos son posesiones físicas y remiten a la expresión corporal del deseo, sea éste divino o carnal. Además, al igual que el baile, el acto sexual como forma de comunión divina es normal en los cultos telúricos, justamente porque favorece la fertilidad de la tierra para que ésta permita cosechas grandes y buenas:

\begin{abstract}
La solidaridad mística entre la fecundidad de la tierra y la fuerza creadora de la mujer es una de las intuiciones fundamentales de lo que podríamos llamar la "conciencia agraria" [...]. Evidentemente, si la mujer ejerce semejante influencia sobre la vegetación, la hierogamia e incluso la orgía colectiva tendrán, con más razón, las más felices consecuencias para la fecundidad vegetal (Eliade 1992: 301).
\end{abstract}

Dos elementos me interesa señalar: el sexo religioso y el papel de la mujer en estos cultos. Pero vamos en orden. Como se puede notar, el objetivo de la sexualidad sagrada es unirse a la Madre Tierra, establecer un vínculo entre los feligreses y la divinidad mediante el coito místico. Las ceremonias y ritos sexuales son muy comunes en estas religiones y van desde las mujeres desnudas que siembran las primeras semillas hasta las parejas de jóvenes que copulan sobre la tierra para unirse a ella y fertilizarla (Eliade 1992: 321). Así, mediante el coito sagrado se logra una cercanía con la divinidad.

Es de sobra conocida la relación del católico con el sexo: es el pecado original, la degeneración, lo que rompe el vínculo entre el ser divino y el ser humano. Para el catolicismo, considerar la posibilidad de un coito místico con Dios, más que blasfemia, sería excomunión segura y condena sempiterna a los fuegos horrendos del infierno. Por ello, el arrebato místico de la instancia narrativa en "Misa de ocho" -tan teñido por el matiz erótico- es totalmente ajeno a la tradición católica y, más bien, se encuentra vinculado con las religiones ctónicas precristianas; es en ellas donde encontramos un referente cultural para la posesión erótica sagrada que sucede en el relato.

Ahora, el segundo punto que deseo recalcar es el papel de la mujer en los cultos telúricos. $\mathrm{Su}$ valor es, obviamente, fundamental pues ella encarna la fertilidad de la tierra, de su vientre nacen los nuevos seres, ella es la que otorga el regalo máximo: la vida. La identificación entre mujer y tierra es total ${ }^{7}$. De manera que, si la tierra es metáfora de la mujer, entonces el arado será metáfora del falo y, por ello, la agricultura lo será a su vez de la relación erótica (Eliade 1992: 238). De nuevo aparece, en las religiones ctónicas, el vínculo entre sexualidad y divinidad ${ }^{8}$.

Esta unión entre lo femenino y lo telúrico termina por establecer en la Europa precristiana, a la Tierra como Triple Diosa -Madre, Ninfa y Virgen (Graves 1998: 19-21)- y a la mujer como su sacerdotisa, maestra en los secretos de la Naturaleza. Estas religiones antiguas, centradas en el principio femenino, son luego malditas por el catolicismo y marcadas como paganismo, como brujería (Michelet 1885: 65). Y, por supuesto, los ritos sexuales a la naturaleza que tenían lugar en estos cultos son convertidos en satanismo, en aquelarres brujeriles (Quaife 1989: 85) o en misas negras (Adams 1966: 61). De modo que, partiendo de esta idea, la instancia narrativa de "Misa de ocho" actúa como una bruja, adora a su divinidad 
personal de la misma manera en que las brujas rendían culto a la naturaleza: con un arrebato místico erótico, corporal, físico.

La relación del texto con los cultos precristianos a la naturaleza se fortalece si recordamos la manera en que la instancia narrativa personifica a la luz, al color y a la música, en una suerte de animismo, al estilo de las religiones paganas:

\footnotetext{
La maravillosa luz [...] se arrodilla sobre los reclinatorios, se acuesta en el mosaico y se soba suavemente con las molduras doradas del altar. (Oreamuno 2003: 140).
}

El color [...] es un personaje solitario y uniforme (Oreamuno 2003: 140).

\section{Y vuelve otra vez la música a correr por la iglesia, a buscarse en los rincones, a brincar de un punto a otro, a ponerse seria y santurrona, a bailar... (Oreamuno 2003: 143).}

Estos personajes, como la instancia narrativa, realizan acciones de adoración a la divinidad: la luz se arrodilla, el color va a la misa católica, la música es ceremonia mística9 (141). En otras palabras, todas las cosas cobran vida para adorar a Dios. Lejos de tratarse de un panteísmo, estamos ante un animismo pagano. Esto porque el panteísmo cristiano de Spinoza plantea que la divinidad se encuentra en todo el universo, que todos los elementos del cosmos son expresiones de los atributos de Dios (Stanford 2004). Dicha visión implicaría que todas las cosas son, en realidad, Dios; por lo que la luz, el color y la música serían parte de Dios. Lo planteado por el relato de Oreamuno, en cambio, es que los elementos tienen vida propia e independiente y, durante la ceremonia, se dedican a adorar a la divinidad, la cual -se deduciría- es una entidad separada de ellos y de la instancia narrativa. De modo que la caracterización de la luz, del color y de la música como entidades personificadas, esconde el sustrato de un animismo propio de las religiones paganas.

Como se puede notar, el modo de experiencia mística que plantea la "Misa de ocho", está fuertemente relacionado con los rituales paganos de comunión con la divinidad ctónica. Por ello, es claro que el relato describe un arrebato místico erótico, más que de un éxtasis metafísico como el de los escritores católicos. Tener sexo con la divinidad para anular el yo, para fusionarse con la totalidad cósmica de la naturaleza. Divinidad física, naturaleza primordial. Comunión sensual. Adoración erótica. Brujería.

\section{Finis naturae}

Cabría preguntarse por qué aparece este sustrato cultural europeo precristiano en el texto de una costarricense. ¿Pose? ¿Europeización? ¿Cosmopolitismo? Eterna pregunta cuando se trata de debatir acerca de la "honestidad" y "autenticidad" de la literatura latinoamericana. Recordemos que este debate ha sido recurrente en el arte de nuestra América: ¿se debe ser regionalista o vanguardista?, ¿indigenista o europeizado?, ¿costumbrista o modernista? El Regionalismo acusa a las vanguardias de falsa; el costumbrismo estigmatiza al modernismo como exotizante. Y, sin embargo, ya Darío, Carpentier, Borges, Paz y tantos otros, han reclamado el derecho para la literatura latinoamericana de aceptar todos los componentes de su tradición cultural: indígenas, europeos, africanos, asiáticos, etc. Si la particularidad cultural americana es ser mestiza, el famoso "crisol de culturas", entonces es deber del americano aceptar la diversidad para poder aceptarse a sí mismo. Y esto implica aceptar toda tradición cultural que esté presente en nuestra tierra: desde Grecia hasta Chichén Itzá, 
desde Judea hasta Etiopía, desde Egipto hasta París. Repudiar a alguna de ellas es negar una parte de nuestra América.

Ya la vanguardia había conquistado este derecho. La propia Yolanda Oreamuno, en su ensayo "Protesta contra el folklore" (1961: 96), repudia el criollismo, esa obligatoriedad promovida por algunos escritores que, de tan obnubilados por una parte de la tradición americana, olvidan muchísimas otras vetas artísticas. Ella misma se declara con autoridad para explorar caminos literarios ajenos al regionalismo. Es uno de los rasgos que le da tan fuerte valor histórico a su literatura.

Y, sin embargo, muy poco debería importarnos lo que ella hubiera dicho. No se debe caer en la tentación de hacer una analogía de Yolanda con sus textos, en un biografismo decimonónico. Es irrelevante si ella conoció los mitos célticos; da igual si le importaban en algo, es indiferente si los incluyó intencionalmente. Sólo importa el texto y en el texto están presentes. Ya conocemos la categoría teórica de "sujeto cultural" para explicar la presencia y la validez de los mitos telúricos europeos precristianos en América Latina. Por supuesto, nunca se encontrarán como una dominante cultural, pues ya fueron conquistados por el catolicismo.

Y, sin embargo, la larga historia de la humanidad nos ha demostrado cómo, cada vez que una civilización devasta a otra, siempre quedan resabios de lo que anteriormente existió. Las palabras náhuatl en el español de América, los festejos paganos en el catolicismo, las ruinas en Hiroshima, los edificios latentes bajo el lago del Arenal. Nunca la muerte es absoluta, nunca el exterminio puede ser completo.

Por eso el misticismo pagano, sea maya o céltico, mandinga o romano, se infiltra en el culto al Dios Padre. Ese asombro máximo ante el universo, esa comunión cósmica que llamamos experiencia mística está permeada por la diosa de la marginación. El poder de la Naturaleza Madre sobrevive en las once mil vírgenes de América, en la santería cubana y el vudú haitiano, en los muertos de México, en la antropofagia simbólica del catolicismo, en el baile místico erótico de la bruja Oreamuno. La destrucción nunca es eterna. De la noche horrenda nace un nuevo día; el invierno asesino da paso a una nueva primavera; el volcán devastador fertiliza la hierba que vendrá más verde; de la destrucción divina, renace el mundo. Siempre hay esperanza. ¿Ilusión? ¿Sueño? ¿Utopía? Tal vez. Pero no por imposible es menos poderosa.

\section{Notas}

1. Por supuesto que el bautismo y la primera comunión son ritos de suma importancia en el catolicismo; pero, en la medida en que suceden sólo una vez en la vida (como ritos iniciático y de tránsito (Eliade 1983a: 155), respectivamente), es la misa el rito que garantiza la cercanía con la divinidad, la constancia de la fe.

2. La instancia narrativa en "Misa de ocho" nunca define su género sino que, más bien, se mantiene neutro. Por otro lado, a pesar de que, como veremos más adelante, el narrador se relaciona con los rituales paganos telúricos que eran oficiados por sacerdotisas, no existen elementos en el texto que permitan afirmar que se trata de un narrador femenino. Antes bien, la relación erótica que el narrador establece con la música y el hecho de que se refiere a ella usando con regularidad el pronombre femenino, sugieren que podríamos entender un narrador masculino. Sin embargo, dada la coincidencia en castellano del género masculino con el neutro, ninguno de los dos casos se puede tomar como definitivo. Además, siempre puede considerarse la posibilidad de un acto homoerótico. 
3. La presencia de Dios en el relato, podría visualizarse desde una perspectiva psicoanalítica. Me explico. El cuento menciona en tres ocasiones la aparición de un "hueco", relacionado con la luz, el color, la música: "el hueco es el marco y la luz" (139); "el rostro y el cuerpo son un hueco para llenar de fantasía" (140); "se nota la ausencia del tema musical, ha dejado un hueco en el ambiente imposible de llamar" (142). Para el psicoanálisis (Baudes 1995: 78), el hueco es metáfora de lo real y Dios, a su vez, en tanto representa la totalidad, es también metáfora de lo real que es, además, indecible ("imposible de llamar"). Ello establece una equivalencia entre Dios y el hueco que plantearía que, cuando hay un hueco, hay Dios. Sin embargo, para ser más convincente en este aspecto, debería incurrir en reflexiones que ahora, por cuestiones de tiempo y espacio, no puedo desarrollar.

4. Durante las jornadas en honor de Yolanda Oreamuno, María Amoretti me sugirió que podía existir una relación entre el éxtasis danzante de la instancia narrativa en "Misa de ocho" y el famoso baile de Salomé, para incitar a Herodes a cortar la cabeza de Juan, el Bautista. Sin embargo, tras algunas reflexiones, no creo que haya relación más allá del matiz erótico de los bailes, pues ambas danzas tienen motivos muy distintos: la de Oreamuno busca adorar a la divinidad, vincularse con la totalidad cósmica; mientras la de Salomé busca la muerte de un hombre, de un profeta, por un simple despecho amoroso. Desde este punto de vista, en tanto el baile de Oreamuno es divino, el de Salomé sería cruel y vengativo.

5. Por supuesto que todo rito se lleva a cabo en el mundo físico humano para apelar al mundo metafísico divino, desde la oración católica hasta el baile erótico. Sin embargo, el catolicismo rehúye -excepto por la ingestión de la hostia- toda realización del rito en el cuerpo, propiamente dicho; mientras que los rituales de adoración a la tierra exigen suceder en el cuerpo, en la medida en que buscan reproducir corporalmente, en los participantes, lo que se desea de la tierra.

6. Los ritos de muchas religiones cristianas contemporáneas no católicas (como los evangélicos o los testigos de Jehová) incluyen la adoración mediante el baile y los cantos de tempo acelerado, así como ritmos populares, desde el rock metálico hasta el merengue y las rancheras. A partir de lo que planteo respecto del cuento de Oreamuno, es en un sustrato pagano en donde se encuentra el motivante de esta necesidad de experimentar corporalmente la presencia de la divinidad.

7. Algunos estudiosos consideran, inclusive, que el vínculo entre mujer y tierra se remonta a las épocas más antiguas, cuando el hombre salía a cazar y, mientras tanto, la mujer esperaba, veía el fluir del tiempo, presenciaba la germinación de las semillas y aprendió, así, a cultivar la tierra (Eliade 1992: 236-241).

8. Esta interpretación se ve fortalecida por la presencia del elemento acuático en la misa. La instancia narrativa describe metafóricamente el tema musical relacionándolo con el agua: "El tema musical [...] se mantiene alterando sólo su superficie con pequeñas ondulaciones que convergen en el centro. [...] se desmorona como una columna de agua en gotas cristalinas que siguen cayendo, cayendo por un rato. [...] Es una cosa brotada de una superficie de agua tensa y quieta y que va ornando redondelas crecientes, resbalosas de la una a la otra" (Oreamuno 2003: 141-2).

9. Como ya había comentado, el tema musical realiza una serie de acciones referidas por la instancia narrativa mediante una descripción metafórica cargada de sinestesias: sale de un hueco, se eleva a un tono más agudo, luego baja, se sostiene, cae, se repite, desaparece y "surge transformado" (141-2). Este proceso también está relacionado con los ritos de sacrificio y resurrección originarios de los cultos agrícolas y de la naturaleza. Dicho proceso viene de los ciclos de muerte y renacimiento del mundo, propios de las estaciones climáticas y se representan en ritos que van desde el sacrificio regenerador como repetición ritual de la creación (Eliade 1992: 312) hasta los enterramientos simbólicos para "regenerar por el contacto con las fuerzas de la tierra, morir a una forma de vida para renacer a otra" (Chevalier 1999: 993). Así, los cultos a la tierra recrean la muerte como símbolo de regeneración, de renacimiento y, si consideramos que el coito es un arrebato extático semejante a la muerte (Freud 2003a: 212), es factible relacionar el coito sagrado con la muerte ritual, ceremonia mística destinada a vincular al oficiante con la divinidad y a favorecer el renacimiento del mundo. 


\section{Bibliografía}

Adams, Louis. 1966. Las misas negras. Barcelona: Editors.

Baudes de Moresco, Mercedes. 1995. Real, simbólico, imaginario. Buenos Aires: Lugar.

Chevalier, Jean y Alain Gheerbrant. 1999. 6ª ed. Diccionario de los símbolos. Barcelona: Herder.

Daxelmüller, Christoph. 1997. Historia social de la magia. Barcelona: Herder.

Eliade, Mircea. 1983a. Lo sagrado y lo profano. $5^{\mathrm{a}}$ ed. Barcelona: Labor.

1992. Tratado de historia de las religiones. México: Era.

1983b. Mito y realidad. $5^{\mathrm{a}}$ ed. Barcelona: Labor.

2001. Mitos, sueños y misterios. Barcelona: Kairós.

Freud, Sigmund. 2003a. "Estudios sobre la histeria (J. Breuer y S. Freud) (1893-1895)". Obras Completas. $2^{\mathrm{a}}$ ed. Buenos Aires: Amorrortu. Vol. II.

2003b. “Tótem y tabú”. Obras Completas. Buenos Aires: Amorrortu.

Graves, Robert. 1998. El vellocino de oro. $2^{\text {a }}$ ed. Barcelona: Edhasa. Vol. XIII.

2002. Los mitos griegos. $2^{\mathrm{a}}$ ed. Madrid: Alianza. Volúmenes I y II.

Michelet, Jules. 1885. La bruja. Barcelona: Ediciones Luis Tasso Serra.

Nietzsche, Friedrich Wilhelm. 1999. El Anticristo (Una maldición sobre el cristianismo). Madrid: Editorial Alba.

Oreamuno, Yolanda. 1961. A lo largo del corto camino. San José: Editorial Costa Rica 2003. Valle alto. San José: EUNED.

Peyret, Alejo. 1917. La evolución del cristianismo. Buenos Aires: Ediciones La cultura Argentina.

Quaife, G. R. 1989. Magia y maleficio: Las brujas y el fanatismo religioso. Barcelona: Crítica. 
Real Academia Española. 2001. Diccionario de la lengua española. 22a ed. Madrid: Espasa Calpe.

Sichère, Bernard. 1995. Historias del mal. Barcelona: Gedisa.

Stanford Encyclopedia of Philosophy. Entrada: "Baruch Spinoza". http://plato.stanford.edu/ entries/spinoza. Consulta: 22 de junio de 2004. 